\title{
Purchasing Power Parity Between Vietnam and United States
}

\author{
Hoang Thi Du ${ }^{1, *}$, Nguyen Xuan Tho ${ }^{2}$ \\ ${ }^{1}$ Department of Finance \& Banking Nha Trang University, Nha Trang, Vietnam \\ ${ }^{2}$ College of Business Southern Taiwan University of Science and Technology, Taiwan \\ 1'duht@ntu.edu.vn", ${ }^{2}$ thochit2009@gmail.com \\ * corresponding author
}

\begin{abstract}
This study uses the annual data of consumer price index, exchange rate and inflation rates spanned from 1986 to 2014 in order to observe whether the PPP hypothesis holds between Vietnam and United States. First, the findings come out based on the graph approach which is used in order to examine both short-run and long-run PPP. Second, the Engle-Granger approach is applied in order to test for the long - run PPP again. In the short-run, the result from the graph approach indicates that PPP holds during hyperinflation years. After hyperinflation period, the exchange rate and relative price tend to be close together in several years. This finding in the short-run seems to reveal a good guide in the long-run PPP. Both graph and the Engle-Granger approach show the same result in the long -run. Upon the stationary testing, the finding of the Engle-Granger approach demonstrates that residuals from the estimation are stationary, therefore, there is an existence of a long-run relationship between nominal and real exchange rate. In other way, PPP seems to hold between Vietnam and United States. The result leads to the implication that multinational companies should set the same prices for products in Vietnam and United States market based on PPP. Otherwise, investors can gain profit through arbitrage strategies.
\end{abstract}

Keywords: Purchasing Power Parity, Exchange Rate, Relative Price

\section{Introduction}

In practice, purchasing power parity (PPP) is widely popular and used by many organizations, companies and investors. Therefore, PPP presents its vital role in many aspects. First, it is considered as a good tool to compare the economic performance and position of different countries. The reason is that PPP rate is not subject to extreme fluctuations and typically only changes over years. Second, it allows to know the potential of an overvalued or undervalued currency. According to PPP, overvalued of undervalued currencies are likely to correct over time, and these changes lead to potential impacts in economy and long-term fluctuations in the exchange rate. PPP may help to give some predictability to these economic impacts. Particularly, if a local currency which is significantly overvalued can be expected to depreciate against widely traded currencies like USD over the long-run. Based on the role of PPP, it becomes a good tool for user in order to compare data, predict data related to exchange rate. For those reasons, testing for the long-run PPP between Vietnam and United States becomes interesting. It reveals a useful insight into whether or not the competitiveness between countries keeps constant over time and provides insight on the potential of an overvalued or undervalued currency. Additionally, it would like to answer whether the application of PPP for the case of Vietnam in practice over the decades is dependable or not. If PPP holds, it still confirms again the vital role of PPP in theory and practice as well. In opposite, if PPP does not hold, it will question the problem of application of PPP in practice. This paper is organized as follows: Section 2 discusses the related literature. Section 3 then demonstrates graph and Engle-Granger approach. Next, section 4 describes the preliminary analysis and presents empirical evidence. Finally, section 5 illustrates the conclusions. 


\section{Literature Review}

In international economics, PPP is one of the interesting topics and has a lot of inspiration for researchers. However, the application of PPP is still a question when the gap between theory and practice always exists. That is why studies on PPP never stops over time. Some studies might support PPP while some would have an opposite evidence and some could find a mixed result. In the years of 1970, PPP is considered as the most important variable determining the exchange rate [1]. A study in a developing country also leads to the same direction conclusion by considering the validity of long-run PPP and using a sample of nine principal trade partners of Algeria. The findings demonstrate that the movements of bilateral exchange rates tend to support the purchasing power parity hypothesis [2]. Using a sample of 15 Latin American countries with monthly data to test PPP hypothesis. The results indicate that PPP holds in many of the Latin American countries studied [3]. Testing PPP theory by applying a panel stationary test with both sharp and smooth breaks for emerging markets. There are findings which provide strong support for PPP in these emerging countries [4]. In the late 1980s, a study of Taylor found an evidence that does not support for PPP. Using econometric techniques on the cointegration of economic time series to observe an empirical analysis of long-run PPP for five major exchange rates, the study rejected the hypothesis of cointegration of the exchange rate and relative prices for any of the countries concerned [5].

A recent study seemed to have the same conclusion as Taylor when analysing the PPP hypothesis in China by using the data of real exchange rates (CNY/USD). The results lead to the conclusion that the long-run PPP hypothesis in China does not hold over the sample period January 1994 to November 2010 [6]. A recent study also found that the evidence in favor of PPP is very weak when using monthly time series data for not less than 64 countries and a new sequential approach to test for PPP [7]. While a study has a mixed result by testing the validity of long-run purchasing power parity for 20 African countries using quarterly data. The empirical results reveal that PPP hypothesis is only suitable for 10 out of these 20 African countries [8]. By applying the panel unit root test to real exchange rate data of eleven Euro countries, another study also releases a mixed finding. The PPP hypothesis were supported by some countries but got contrary evidence by remained countries [9]. Considering the lack of power of test of non-purchasing power parity, some economists point out that the tests typically employed to determine the long-run stability of the real exchange rate, if based on data covering over a relatively short period, for instance: 15 years, may not have enough yield information to reject the null hypothesis [10].

\section{Methodology}

\subsection{Sample Data}

This study uses the annual data spanned from 1986 to 2014 including consumer price index, inflation rate which are collected from Econstats, World Economic Outlook data, IMF, and yearly nominal and real VND/USD rate of exchange rate which is collected from the website: http://www.worldbank.org.

\subsection{Model Identification}

\section{- Graph approach}

the exchange rate from the absolute PPP equation and the rate of depreciation from relative PPP formulation, this data is sketched on figures.

The absolute PPP is calculated as follows:

$$
E_{\text {vnd / usd }}=\frac{P_{V N}}{P_{U S}}
$$

Where Evnd/usd denotes the exchange rate between VND and USD; PVN presents the good's price in Vietnam and PUS demonstrates the good's price in United States. In other words, indicates the ratio of price levels. The relative PPP is presented in the below equation: 


$$
\frac{\Delta E_{\text {vnd / usd }}}{E_{\text {vnd / usd }}}=\pi_{V N}-\pi \pi_{U S}
$$

Where $\frac{\Delta E_{\text {vnd /usd }}}{E_{\text {vnd /usd }}}$ denotes the rate of depreciation of the nominal exchange rate and $\pi_{V N}-\pi_{U S \text { presents }}$ the inflation differential between Vietnam and the United States.

In the short-run, if PPP holds, the relative price level $\left({ }^{\frac{P_{V N}}{P_{U S}}}\right)$ and exchange rate (Evnd/usd) should drift together over decades (Feenstra and Taylor 2011, 467). In the long - run, if all the data points (rate of depreciation and inflation differential) appear on the 45-degree line, it means that PPP holds.

\section{- Engle-Granger approach}

Purchasing power parity states that the equilibrium or long-run exchange rate between two countries is equal to the ratio of their relative price levels. Purchasing power parity implies that the real exchange rate $q V N / U S$, is stationary (Brooks, 2008, 355). The real exchange rate can be defined as follows:

$$
q_{V N / U S}=\left(E_{V N D / U S D} P_{U S}\right) P_{V N}
$$

Where $q V N / U S$ denotes the real exchange rate between VND and USD; (EVND/USD presents the nominal exchange rate between VND and USD; PUS demonstrates the foreign price level and PVNis the domestic price level. Take the logarithms of the formulation (3.3), the equation (3.4) is the logarithmic transforms of the corresponding case used in (3.3)

$$
\ln \left(q_{V N / U S}\right)=\ln \left(E_{V N D / U S D}\right)+\ln \left(P_{U S}\right)-\ln \left(P_{V N}\right)
$$

The excel and Eview 7.0 software are used in order to perform research process as well as obtain research findings.

\section{Empirical Result}

\subsection{Data Description}

The chart of figure 1 shows the consumer price index of Vietnam and the United States from 1986 to 2014. It indicates that both the CPI of Vietnam and the United States have had an upward trend over time. The CPI of the United States fell down in 2009. This year, the United States has the impact of the 2008 financial crisis which leads to weak demand and price of goods fell down, especially, the fall in computer and gasoline price. In Vietnam, this country experienced two years of mild deflation in 2000 and 2001, the main reason is the unbalance in supply and demand and the decrease in FDI inflows. 


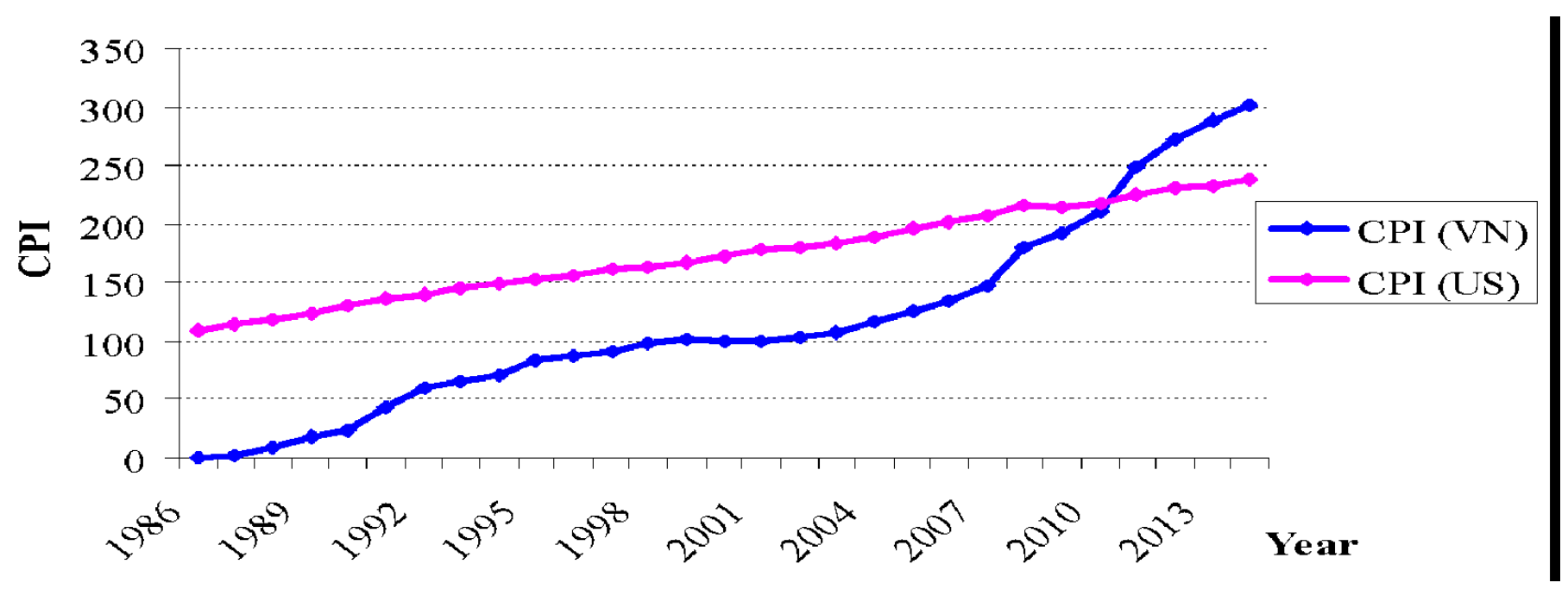

Figure. 1. Consumer Price Index of Vietnam \& United States, 1986-2014

The figure 2 indicates the nominal and real VND/USD rate from 1986 to 2014. The nominal VND/USD rate was significantly depreciated while real exchange rate fluctuated a lot overtime.

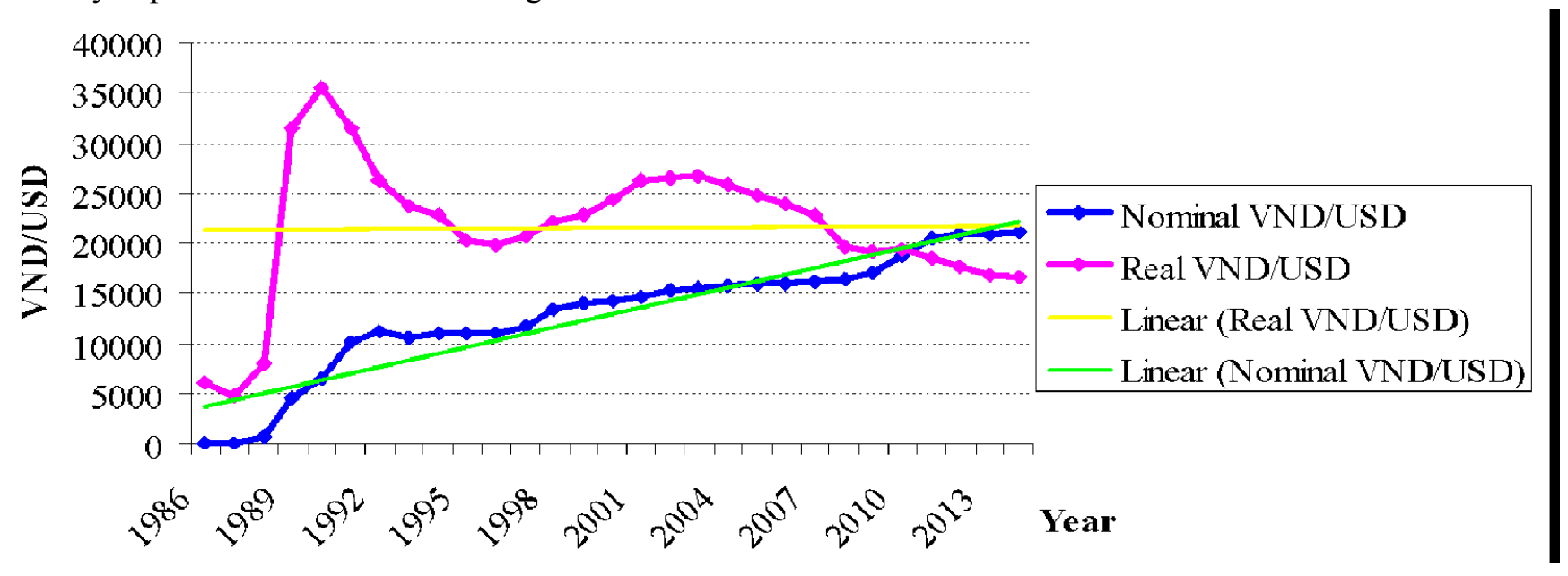

Figure. 2. Yearly Nominal and Real Exchange Rate, 1986-2014

The figure 3 demonstrates the inflation rate of Vietnam and United States from 1986 to 2014. It shows that Vietnam experienced a hyperinflation period from 1986 to 1988 (over 300\% in average). The reason is that Vietnam made renovation policy "Doi moi" in 1986 to transform the system from central management to free market. The government tried use tight money and fiscal policy to control inflation overtime. Until 1992, the inflation rate reduced to 38\%. Vietnam also experienced two years of mild deflation in 2000 and 2001. In 2008, there is high inflation with the affection of financial crisis as well as increasing of FDI inflows after this country joined WTO. A high inflation still happened in 2011, because the contribution of a sizeable fiscal policy stimulus amounting to around 5 percent of GDP was executed from 2009. In United States, the inflation rate overtime were low. However, in 2009, it suffered from deflation because the affection of financial crisis and recession. Overall, inflation rate in Vietnam fluctuated a lot and much higher than inflation rate in United States. 


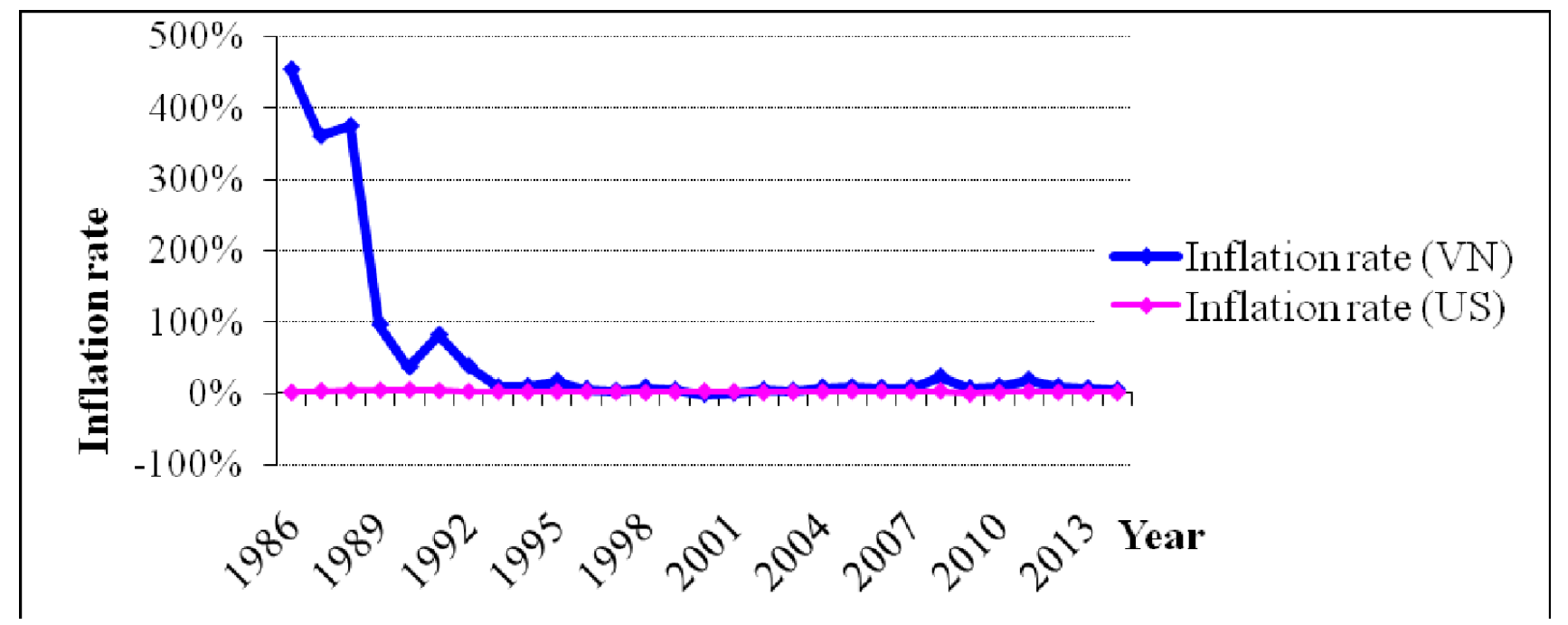

Figure. 3. Inflation Rate of Vietnam \& United States, 1986-2014

\subsection{Graph approach}

The figure 4 shows that the exchange rate and relative price tend to drift together in the short-run. Especially, in the period of hyperinflation, the exchange rate and relative price were very close together. Therefore, PPP holds during these hyperinflation years. After the hyperinflation period, the exchange rate and relative price tend to be close together in several years.

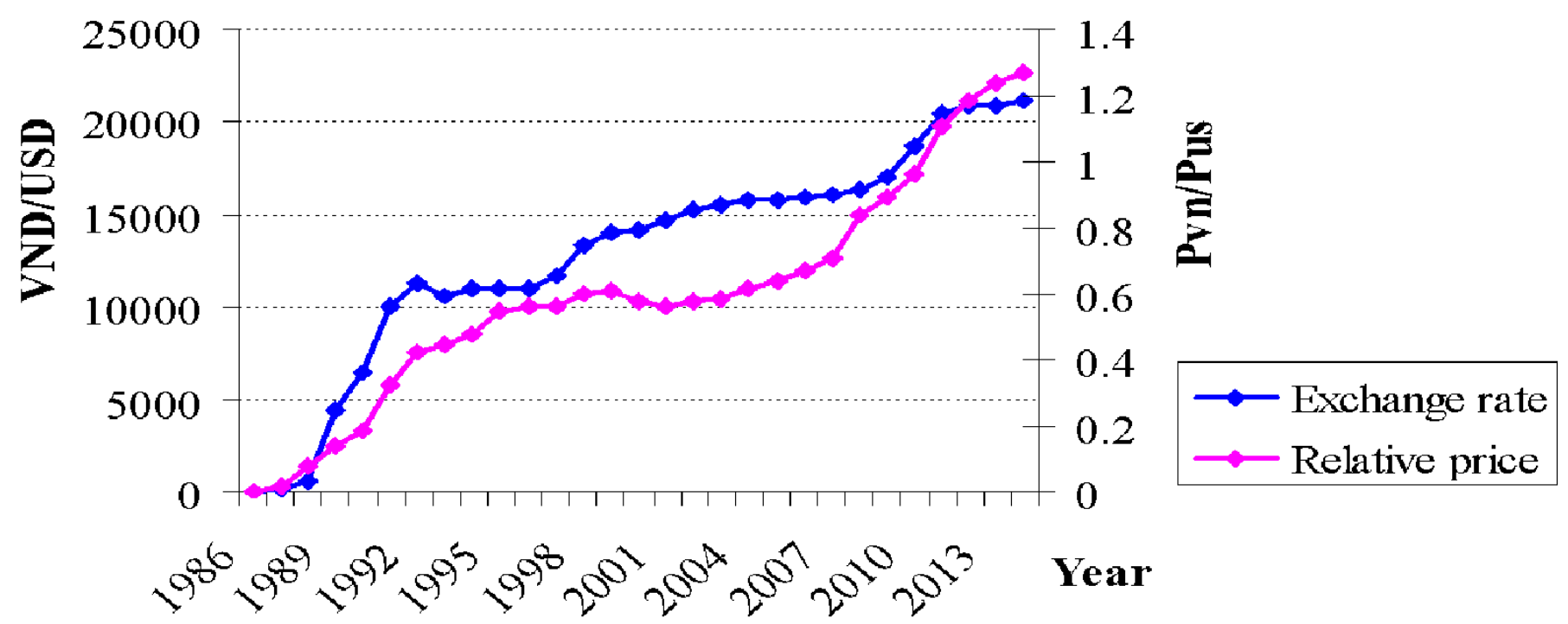

Figure. 4. Exchange Rate and Relative Price Levels

The figure 5 represents the relationship between inflation differential against the United States and the exchange rate depreciation against the U.S.dollar. It shows that most of data points line on the 45-degree line. In other words, this result is close to the theoretical prediction of PPP. 


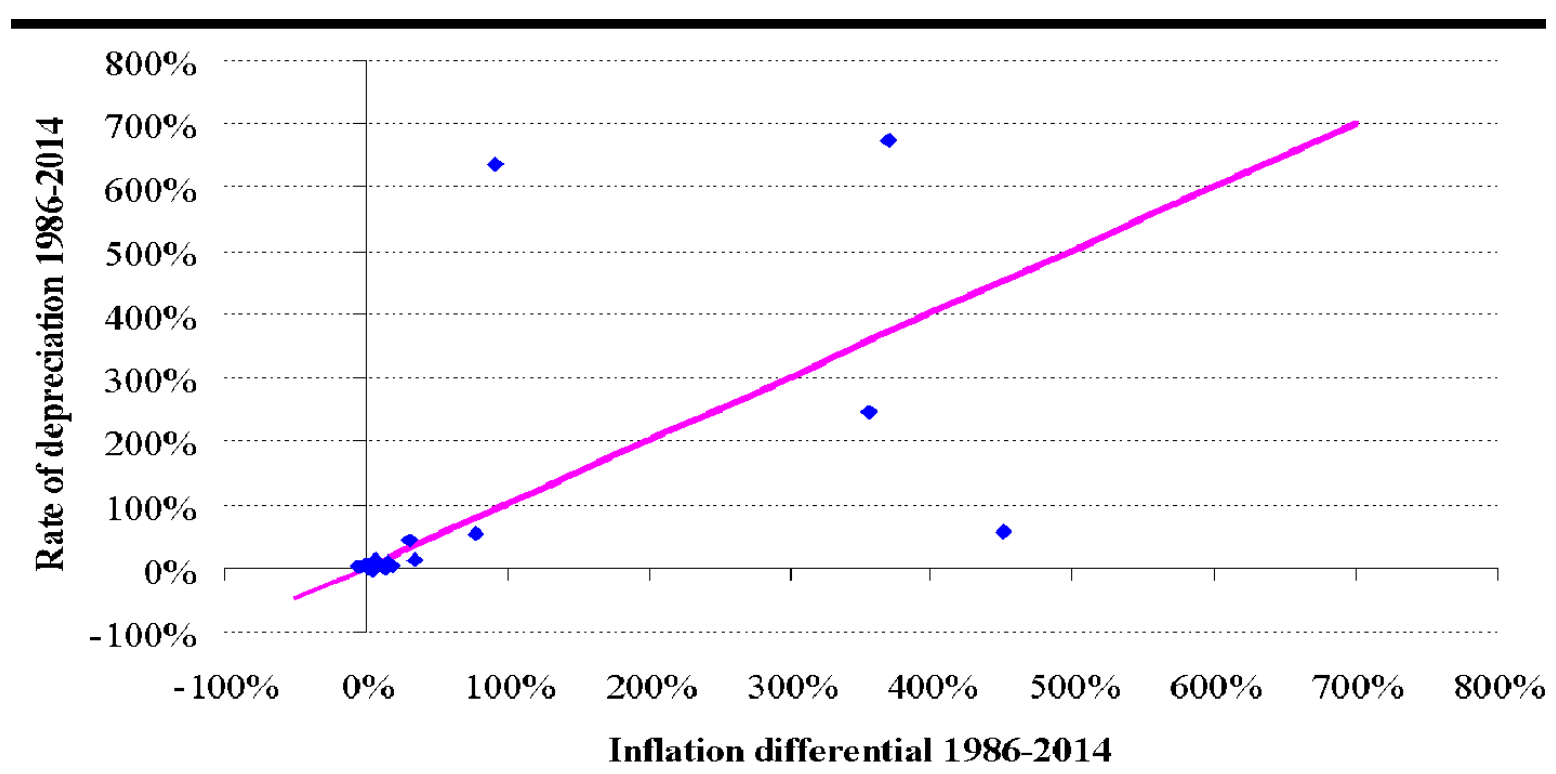

Figure. 5. Inflation Differential and The Exchange Rate, 1986-2014

\subsection{Engle-Granger approach}

Table 1 illustrates the results of stationary testing. Using the Augmented Dickey-Fuller(ADF) and applying for the case of trend and intercept, this study finds that $\ln (\mathrm{EVND} / \mathrm{USD})$ and $\ln (\mathrm{qVND} / \mathrm{USD})$ is stationary at level with order 1 while $\ln (\mathrm{PVN})$ and $\ln$ (PUS) is stationary at the first difference with order 1, based on the smallest AIC and SBC.

Table. 1. Results of Unit Root Test

\begin{tabular}{|l|l|l|l|l|}
\hline Variables & AIC & SBC & Lag & Unit root \\
\hline $\ln \left(\mathrm{E}_{\mathrm{VND} / \mathrm{USD}}\right)$ & $-1.067^{*}$ & $-0.875^{*}$ & 1 & $\mathrm{I}(0)$ \\
\hline $\ln \left(\mathrm{q}_{\mathrm{VND} / \mathrm{USD}}\right)$ & $-0.747^{*}$ & $-0.555^{*}$ & 1 & $\mathrm{I}(0)$ \\
\hline $\ln \left(\mathrm{P}_{\mathrm{VN}}\right)$ & $-1.584^{*}$ & $-6.151^{*}$ & 1 & $\mathrm{I}(1)$ \\
\hline $\ln \left(\mathrm{P}_{\mathrm{US}}\right)$ & $-6.345^{* *}$ & $-1.390^{*} *$ & 1 & $\mathrm{I}(1)$ \\
\hline
\end{tabular}

Notes: First, * denotes the statistical significance at $1 \%$ level and $* *$ denotes the statistical significance at $5 \%$ level which the critical values are decided on the critical value table of Mackinnon (1991). Second, The Augmented Dickey-Fuller(ADF) statistics which the lag interval is determined on the criterions of minimization of AIC and SBC value. The function of $\mathrm{AIC}$ and $\mathrm{SBC}$ areas follows:

$$
\begin{gathered}
A I C(k)=T \cdot \ln +2 k \\
S B C(k)=T \cdot \ln +k \cdot \ln T
\end{gathered}
$$

Where $\mathrm{k}$ denotes the lagged period, $\mathrm{T}$ denotes the number of sample, and $\sigma_{t}^{2}$ denotes the lagged k periods of $\sum_{i=1}^{T} \varepsilon_{t}^{2}$

Table 2 shows the result of OLS regression where the coefficients of all variables are 1.0 and the statistics are significant at $1 \%$ level.

Table. 2. Regression Result 


\begin{tabular}{|l|l|l|l|}
\hline Variables & Coefficient & T-statistic & P-values \\
\hline $\ln \left(\mathrm{E}_{\mathrm{VND} / \mathrm{USD}}\right)$ & 1.0 & 18991914 & 0.0000 \\
$\ln \left(\mathrm{P}_{\mathrm{VN}}\right)$ & 1.0 & 18495917 & 0.0000 \\
$\ln \left(\mathrm{P}_{\mathrm{US}}\right)$ & -1.0 & -18381984 & 0.0000 \\
\hline
\end{tabular}

The table 3 mentions the unit root test for residuals which are obtained from the above regression. The residuals from the estimation are stationary at all the cases and at level with order 1 based on the ADF test. In other words, there is an existence of a long run relationship between nominal and real exchange rate.

Table. 3. Unit Root Test for Residuals

\begin{tabular}{|l|l|l|l|}
\hline Item & Intercept & Trend and Intercept & None \\
& & & \\
\hline AIC & $-28.519^{*}$ & $-28.457^{*}$ & $-28.593^{*}$ \\
\hline SBC & $-28.376^{*}$ & $-28.265^{*}$ & $-28.498^{*}$ \\
\hline Lag & 1 & 1 & 1 \\
\hline Unit root & $\mathrm{I}(0)$ & $\mathrm{I}(0)$ & $\mathrm{I}(0)$ \\
\hline
\end{tabular}

\section{Conclusion}

Interested in considering PPP between Vietnam and United States, this study finds some main points from the results. First, in the short-run, the result from the graph approach indicates that PPP holds during hyperinflation years. After hyperinflation period, the exchange rate and relative price tend to be close together in several years. This finding seems to reveal a good guide in the long-run PPP. Both graph and the Engle-Granger approach show the same result in the long -run. Upon the unit root testing, the finding of the Engle-Granger approach demonstrates that residuals from the estimation are stationary, therefore, there is an existence of a long-run relationship between nominal and real exchange rate. In other words, this result indicates that PPP seems to hold between Vietnam and United States. This research result is consistent with other previous studies. It is important for multinational companies to set the same prices for products across different countries, particularly, Vietnam and United States. If there are prices for the same product that are different between countries, it is not sustainable. This is because it allows someone to buy the product in the cheapest market and sell it for a higher price in another market to gain arbitrage profit. On the other hand, exchange rate tends to move in the direction of the PPP exchange rate, therefore, it can help to determine exchange rate trend in the long run. In practice, PPP can be used by some forex trader to find potentially overvalued or undervalued currencies. In addition, foreign investors holding stock or bonds of Vietnamese companies can also predict the impact of exchange rate fluctuations on this country's economy by using PPP figures. In other aspect, the findings of this study are expected to contribute to the literature in PPP, especially, in the case of developing countries.

\section{References}

[1] Officer, Lawrence H., 1976. The purchasing-power-parity theory of exchange rates: A review article. Staff Papers 23(1), 1-60.

[2] Mohammed, Kamel Si., 2015. An empirical test of purchasing power parity of the Algerian exchange rate: evidence from panel dynamic. European Scientific Journal 11(25), 274-287. 
[3] He, Huizhen, Chou, Ming Che, \& Chang, Tsangyao, 2014. Purchasing power parity for 15 Latin American countries: Panel SURKSS test with a Fourier function. Economic Modelling 36, 37-43.

[4] Bahmani-Oskooee, Mohsen, Chang, Tsangyao, \& Lee, Kuei-Chiu, 2016. Purchasing power parity in emerging markets: A panel stationary test with both sharp and smooth breaks. Economic Systems 40(3), 453-460.

[5] Taylor, Mark P. 1988. An empirical examination of long-run purchasing power parity using cointegration techniques. Applied economics 20(10), 1369-1381.

[6] Alberiko Gil-Alana, Luis, \& Jiang, Liang, 2013. The Purchasing Power Parity Hypothesis in the Us-Ch Relationship: Fractional Integration, Time Variation and Data Frequency. International Journal of Finance Economics 18(1), 82-92.

[7] Westerlund, Joakim, \& Narayan, Paresh, 2015. A sequential purchasing power parity test for panels of large cross-sections and implications for investors. The European Journal of Finance 21(15),1317-1333.

[8] Bahmani-Oskooee, Mohsen, Chang, Tsangyao, \& Wu, Tsungpao, 2014. Revisiting purchasing power parity in African countries: panel stationary test with sharp and smooth breaks. Applied Financial Economics 24(22), $1429-1438$.

[9] Huang, Chao-Hsi, \& Yang, Chih-Yuan, 2015. European exchange rate regimes and purchasing power parity: An empirical study on eleven eurozone countries. International Review of Economics \& Finance 35, 100-109.

[10] Taylor, Mark P, 2003. Purchasing power parity. Review of International Economics 11(3), 436-452. 